\title{
In Vitro Study of the Anti-cancer Effect of Alternate- day 5-Fluorouracil in Head and Neck Cancer Cells
}

\author{
YORIHISA MORO ${ }^{1}$, YASUNAO KOGASHIWA ${ }^{2}$, HIROYUKI SAKURAI ${ }^{3}$, RYO TAKAHASHI $^{4}$, TORU KIMURA ${ }^{3}$, \\ MASATAKA HIRASAKI ${ }^{5}$, YOSHIFUMI MATSUMOTO ${ }^{1}$, MASASHI SUGASAWA ${ }^{2}$ and NAOYUKI KOHNO ${ }^{1,6}$ \\ ${ }^{1}$ Department of Otolaryngology, Head and Neck Surgery, Kyorin University School of Medicine, Tokyo, Japan; \\ ${ }^{2}$ Department of Head and Neck Surgery, Otolaryngology, \\ Saitama Medical University International Medical Center, Saitama, Japan; \\ ${ }^{3}$ Department of Pharmacology and Toxicology, Kyorin University School of Medicine, Tokyo, Japan; \\ ${ }^{4}$ Department of Flow Cytometry core facility, Kyorin University School of Medicine, Tokyo, Japan; \\ ${ }^{5}$ Division of Developmental Biology, Research Center for Genomic Medicine, \\ Saitama Medical University, Saitama, Japan; \\ ${ }^{6}$ Department of Otolaryngology, Kosei Hospital, Tokyo, Japan
}

\begin{abstract}
Background/Aim: We have previously reported that alternate-day $S-1$ had comparable effects and milder adverse events than the respective consecutive-day regimen in head and neck cancer (HNC) patients. The aim of this study was to investigate the anticancer effects of both regimens and underlying mechanisms in vitro. Materials and Methods: Two head and neck squamous cell carcinoma (HNSCC) cell lines were treated with 5-FU given on an alternate-day or consecutive-day schedule. The relative inhibition (RI) of tumor growth was calculated. Cell cycle distributions and cyclin expression following 5-FU treatment were analyzed. Results: The RI of both regimens was almost identical. The percentage of cells in $S$ phase was significantly increased in the alternate-day group compared to the consecutive-day group $(p<0.001)$. Conclusion: The cytotoxic effect of alternate-day was equivalent to that of consecutive-day. S-phase arrest was more prominently observed with the alternate-day regimen, which may help maintain 5-FU sensitivity in head and neck cancer cells.
\end{abstract}

Head and neck squamous cell carcinoma (HNSCC) is still lethal because of the high percentage of recurrence and metastasis (1-4). S-1 is a novel oral anticancer agent consisting

Correspondence to: Yasunao Kogashiwa, MD, Ph.D., Department of Otolaryngology, Head and Neck Surgery, Saitama Medical University International Medical Center, 1397-1 Yamane, Hidaka, Saitama 350-1298, Japan. Tel: +81 429844111, Fax: +81 429844741, e-mail: y_koga@saitama-med.ac.jp

Key Words: 5-FU, cyclin, S-1, squamous cell carcinoma, adjuvant therapy. of tegafur, 5-chloro-2,4-dihydroxypyridine, and potassium oxonate at a molar ratio of 1:0.4:1, based on biochemical modulation of 5-fluorouracil (5-FU) $(1,5)$. A phase III study [Adjuvant Chemotherapy with S-1 after Curative Treatment in Patients with Head Neck Cancer (ACTS-HNC) trial] investigated whether adjuvant therapy with $S-1$ could improve the prognosis in head and neck cancer (6). S-1 was administered daily for 2 weeks, followed by a 1-week rest period. The study showed that adjuvant chemotherapy with S-1 resulted in significantly better overall survival (OS) in patients with locally advanced HNSCC compared to the control arm. However, the S-1 arm was less well-tolerated and the 1-year completion rate of S-1 was only $43.4 \%$. Therefore, treatment completion and tolerance remain unresolved problems. Sakuma et al. reported that S-1 given on an alternate-day schedule can reduce the incidence of adverse effects without compromising the therapeutic effects of S-1 (7). The alternate-day regimen was equivalent to or better than the consecutive-day regimen in patients with other regimens for metastatic pancreatic cancer in a clinical trial (8). Likewise, we conducted a retrospective study of an alternate-day S-1 regimen as adjuvant therapy after surgery and chemoradiotherapy for advanced HNSCC. In that study, we observed that alternate-day S-1 administration caused fewer adverse effects and was tolerable for patients with advanced HNSCC (9). The completion rate was $80.7 \%$ and the occurrence of adverse events tended to be less than that reported in the ACTS-HNC trial. Three-year OS and disease-free survival rates were $74.8 \%$ and $57.3 \%$, respectively. Other groups also reported that alternate-day S-1 treatment was associated with milder adverse events without compromising therapeutic effectiveness in clinical or pre-clinical studies in gastric cancer or pancreatic cancer $(7,10)$. Thus, alternate-day S-1 regimen may be an effective adjuvant treatment with 

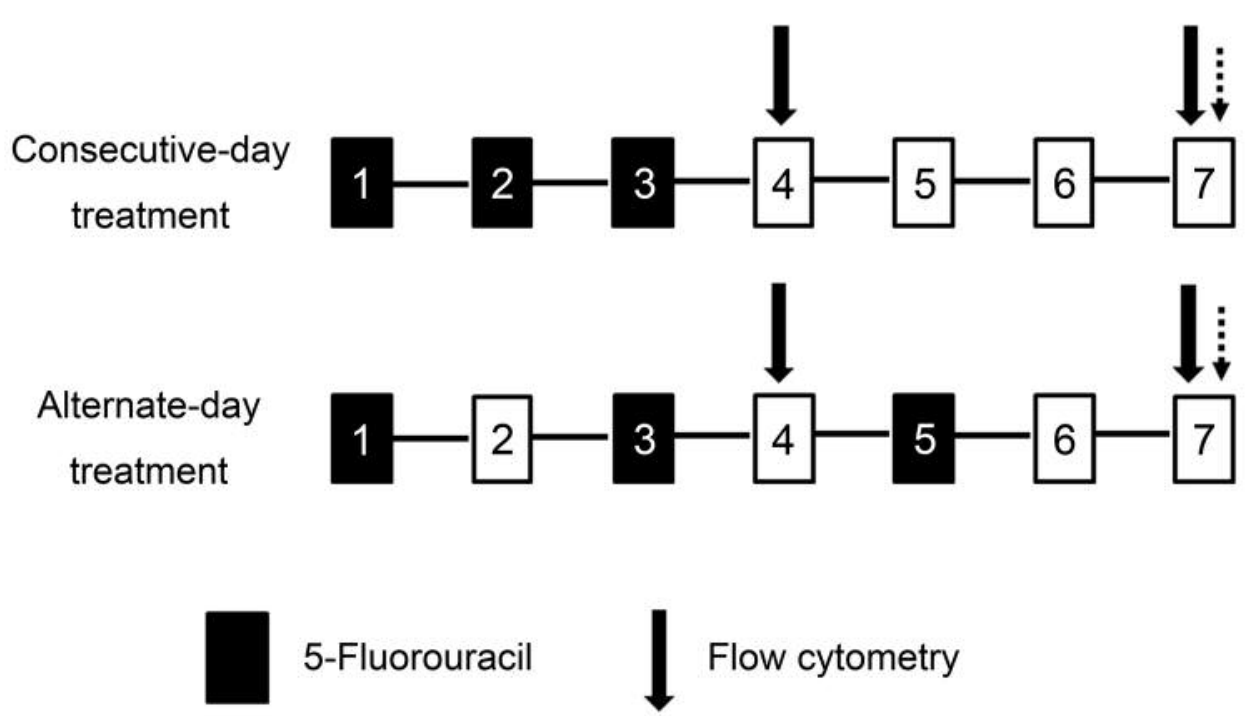

5-Fluorouracil

1

Flow cytometry

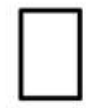

Medium

WST assay, flow cytometry
and western blot analysis

Figure 1. Treatment schedules of 5-fluorouracil were planned to estimate tumor growth inhibition in vitro. For consecutive-day treatment, 5fluorouracil was added on days 1-3 and culture medium was added on days 4-6. For alternate-day treatment, cell cultures were exposed to 5fluorouracil or culture medium every other day (5-fluorouracil was added on days 1, 3, and 5). The time point of the equivalent total dose is day 6.

milder side effects than the original consecutive-day regimen. Here, we investigated anticancer effects and underlying mechanisms of 5-FU given on an alternate-day schedule compared with the consecutive-day schedule in head and neck cancer cells in vitro.

\section{Materials and Methods}

Cell lines and reagents. The HSC-3-M3 cell line (11-13), derived from a patient with oral squamous cell carcinoma, was obtained from the Japanese Collection of Research Bioresources (Osaka, Japan). HSC-3-M3 cells were cultured in Eagle's minimum essential medium supplemented with 10\% fetal bovine serum (FBS), 100 units $/ \mathrm{ml}$ penicillin, and 100 units $/ \mathrm{ml}$ streptomycin in a humidified incubator with $5 \% \mathrm{CO}_{2}$ at $37^{\circ} \mathrm{C}$. The BICR6 cell line (14), derived from a patient with hypopharyngeal cancer, was obtained from the European Collection of Cell Cultures (United Kingdom). BICR6 cells were cultured in Dulbecco modified Eagle's medium supplemented with $10 \%$ FBS, $0.4 \mu \mathrm{g} / \mathrm{ml}$ hydrocortisone, 100 units $/ \mathrm{ml}$ penicillin, and $100 \mu \mathrm{g} / \mathrm{ml}$ streptomycin in a humidified incubator with $8 \% \mathrm{CO}_{2}$ at $37^{\circ} \mathrm{C}$.

5 -FU and dimethyl sulfoxide (DMSO) were purchased from Wako (Tokyo, Japan); stock solutions of 5-FU were made in DMSO and stored at $-20^{\circ} \mathrm{C}$ until use. The final concentration of DMSO was $<0.1 \%$ in the culture medium and the same concentration of DMSO was present in the control group.

Cell doubling time. HSC-3-M3 and BICR6 cells were seeded onto flatbottom 10-cm dishes (NIPPON Genetics, Tokyo, Japan) at a density of 20,000 cells/dish. Doubling time was calculated using the following formula $=\left[\mathrm{T} \times \log _{\mathrm{e}} 2\right] /[\ln (\mathrm{Y} / \mathrm{X})]$, where $\mathrm{T}$ is time in any unit, $\mathrm{X}$ is starting number of cells, and $\mathrm{Y}$ is final number of cells after trypsinization. Proliferation of HSC-3-M3 and BICR6 cells was analyzed by counting the total cell number at $0,24,48$, and $72 \mathrm{~h}(15)$.

Proliferation assay. HSC-3-M3 and BICR6 cells were seeded onto 24-well flat-bottom microdilution plates (Sumitomo Bakelite, Tokyo, Japan) at a density of 1,500 cells/well. Cell suspensions were then transferred to 8 wells each for treatment and control groups. Cell cultures were statically washed three times with culture solution once daily. For consecutive-day treatment, 5-FU was added on days 1-3 and culture medium was added on days 4-6. For alternate-day treatment, cell cultures were exposed to 5-FU or culture medium every other day (5-FU was added on days 1, 3, and $5)$. The control group was exposed to culture medium only. The number of viable cells was determined by addition of WST-8 (Dojindo Laboratories, Kumamoto, Japan) according to the manufacturer's instructions. Data were collected from three independent experiments. Time courses are shown in Figure 1. Halfmaximal inhibitory concentration $\left(\mathrm{IC}_{50}\right)$ values, i.e., drug concentrations at $50 \%$ cell growth inhibition compared with control cell growth, were used in all subsequent experiments.

Inhibition analysis of tumor growth in vitro. HSC-3-M3 and BICR6 cells were seeded onto 24-well flat-bottom microdilution plates (Sumitomo Bakelite) at a density of 1,500 cells/well. Cell suspensions were then transferred to 8 wells each for treatment and control groups. Cell cultures were statically washed three times with culture solution once daily. Time courses were same as described above for the proliferation assay. The optical density in the treatment group was divided by that in the control group to calculate 

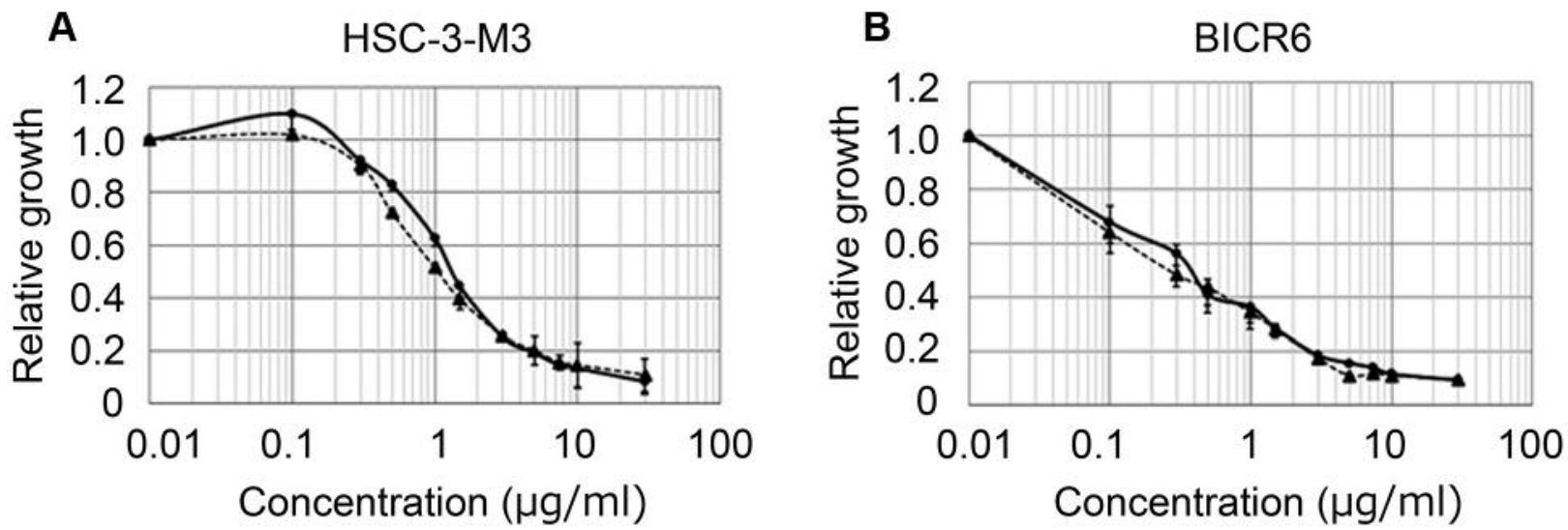

\section{------ Consecutive-day treatment Alternate-day treatment}

Figure 2. In vitro responses of HSC-3-M3 and BICR6 cells to effects of various concentrations of 5-fluorouracil. Cell viability was assessed using the WST-8 assay.

the tumor growth ratio relative to control $(\mathrm{T} / \mathrm{C})$. The relative inhibition (RI) rate of tumor growth was calculated by the following equation: RI $(\%)=(1-\mathrm{T} / \mathrm{C}) \times 100$.

Cell cycle analysis by flow cytometry. Cell cycle analysis is one of the most applied protocols in flow cytometry and is most commonly used to measure frequencies of cells that are either in $G_{0} / G_{1}, G_{2} / M$, or $\mathrm{S}$ phase of the cell cycle. To determine the percentage of cells in various phases of the cell cycle, exponentially proliferating cells were treated with 5-FU. Treated cells and untreated controls were then analyzed for nuclear DNA after propidium iodide staining using the Cycletest ${ }^{\mathrm{TM}}$ Plus DNA Reagent kit (Becton Dickinson, San Jose, CA, USA) according to the manufacturer's instructions. This kit provides a set of reagents for isolating and staining cell nuclei from surplus cell suspensions. Flow cytometric analysis of differentially stained normal and tumor cells was then used to identify abnormal DNA stemlines and estimate the DNA index (DI) and cell-cycle phase distributions of these stemlines. Flow cytometric analysis was performed using the FACSCalibur ${ }^{\mathrm{TM}}$ flow cytometer (Becton Dickinson).

Western blot analysis. Treated cells and untreated controls were washed twice with ice-cold phosphate-buffered saline and then harvested by scraping in Lysis buffer (Cat. No. C3228; Merck, Kenilworth, NJ, USA). After homogenization and centrifugation for $30 \mathrm{~min}$ at $13,000 \times \mathrm{g}$, the supernatants $(20 \mu \mathrm{g}$ of protein) were subjected to SDS-PAGE, followed by transfer to polyvinylidene difluoride membranes (Cat. No. IPVH00010; Merck). Immunoblot analysis was performed on day 7 of treatment using the following primary antibodies: cyclin A (1:200 dilution; ab38), cyclin D (1:20,000 dilution; ab134175), cyclin E (1:1,000 dilution; ab133266), and $\beta$-actin (1:1,000 dilution; ab8226), which were obtained from Abcam (Cambridge, UK). After washing, cells were incubated with horseradish peroxidase-conjugated anti-rabbit IgG or anti-mouse IgG secondary antibody (Jackson ImmunoResearch
Laboratories, West Grove, PA, USA). Images were obtained using Fujifilm LAS-4000 mini (Fujifilm, Tokyo, Japan). Quantification of band density was obtained by ImageJ software (Version 1.5).

Statistical analysis. All data were obtained from triplicate experiments and are expressed as mean \pm standard deviation from triplicate experiments. Student's $t$-tests were employed for analyzing data. All statistical analyses were performed with EZR (13); $p$ values $<0.05$ were considered statistically significant.

\section{Results}

Cell doubling time. Doubling times of tumor cell lines were 24.4 h for HSC-3-M3 and 30.6 h for BICR6.

Determination of $\mathrm{IC}_{50}$ in HSC-3-M3 and BICR6 cells. Antiproliferative effects of 5-FU in HSC-3-M3 and BICR6 cells were determined by the WST assay. The drug inhibited cell growth in a dose-dependent manner and both treatment schedules inhibited cell growth to a comparable degree (Figure 2). IC $_{50}$ of HSC-3-M3 and BICR6 were $1.5 \mu \mathrm{g} / \mathrm{ml}$ and $0.4 \mu \mathrm{g} / \mathrm{ml}$, respectively, in alternative-day treatment.

Inhibition of cell proliferation in vitro. In this study, the experiments were conducted at the same concentration to clarify the differences in growth inhibitory effects when only the administration schedule was changed. Thus, we performed the following experiment at $\mathrm{IC}_{50}$ concentration in alternativeday treatment. The RI of consecutive-day treatment in BICR6 and HSC-3-M3 cell lines was $62.6 \pm 0.6 \%$ and $47.2 \pm 5.3 \%$, respectively, while the RI of alternate-day treatment in BICR6 and HSC-3-M3 cell lines was $61.6 \pm 0.7 \%$ and $46.5 \pm 1.5 \%$, 
Table I. Antitumor effect of 5-fluorouracil (5-FU) on the HSC-3-M3 and BICR6 cell lines.

\begin{tabular}{lccccccc}
\hline & \multicolumn{3}{c}{ HSC-3-M3 } & & \multicolumn{2}{c}{ BICR6 } \\
\cline { 2 - 3 } & WST (OD) & RI* $(\%) \pm$ SD & $p$-Value & & WST (OD) & RI* (\%) \pm SD & $p$-Value \\
\hline Control & 1.526 & & & & 1.629 & \\
Consecutive-day treatment & 0.571 & $62.6 \pm 0.6$ & 0.14 & & 0.859 & $47.2 \pm 5.3$ & 0.70 \\
Alternate-day treatment & 0.585 & $61.6 \pm 0.7$ & & & 0.871 & $46.5 \pm 1.0$ \\
\hline
\end{tabular}

WST, WST cell proliferation assay; OD, optical density; RI, relative inhibition; SD, standard deviation. *RI $(\%)=(1-\mathrm{T} / \mathrm{C}) \times 100$, where T/C represents the tumor growth ratio relative to control (T/C), calculated as optical density in the treated group was divided by that in the control group.

respectively. The difference in the RI between consecutive-day treatment and alternative-day treatment was not statistically significant (Table I). Saga et al. reported that the drug-free interval in the intermittent infusion of 5-FU had to be shorter than the doubling time of targeted tumor cells to obtain a similar killing effect as continuous administration in vitro (14). As shown above, the two cell lines tested showed doubling times of $>24 \mathrm{~h}$; thus, we speculated that alternative-day 5-FU treatment achieved a similar killing effect as consecutive-day treatment in the two cell lines.

Alternate-day treatment with 5-FU prolonged the $\mathrm{S}$ phase in HSC-3-M3 and BICR6 cells compared to consecutive-day treatment and control. 5-FU only targets cycling cells and modulates cancer cell cycle status, and 24-h exposure to 5-FU is associated with an accumulation of cells in $\mathrm{S}$ phase (1). The population of HSC-3-M3 cells in S phase on day 4 of treatment was $25.9 \pm 2.2 \%$ in the control group, $75.2 \pm 3.8 \%$ in the consecutive-day treatment group, and $55.4 \pm 5.4 \%$ in the alternate-day treatment group. The population of BICR6 cells in $\mathrm{S}$ phase on day 4 of treatment was $32.8 \pm 2.6 \%$ in the control group, $68.7 \pm 5.4 \%$ in the consecutive-day treatment group, and $58.9 \pm 5.9 \%$ in the alternate-day treatment group (Figure $3 \mathrm{~A}$ ). The population of HSC-3-M3 cells in S phase on day 7 of treatment was $15.1 \pm 2.5 \%$ in the control group, $22.7 \pm 4.5 \%$ in the consecutive-day treatment group, and $54.3 \pm 6.8 \%$ in the alternate-day treatment group. The population of BICR6 cells in $S$ phase on day 7 of treatment was $20.0 \pm 3.5 \%$ in the control group, $38.3 \pm 3.7 \%$ in the consecutive-day treatment group, and $57.1 \pm 4.8 \%$ in the alternate-day treatment group (Figure $3 \mathrm{~B}$ ). In consecutive-day treatment, the percentage of cells in $\mathrm{S}$ phase on day 7 of treatment was significantly decreased compared to that on day 4 of treatment in HSC-3-M3 and BICR6 cells $(p<0.05)$ (Figure 3C). In alternate-day treatment, the percentage of cells in $\mathrm{S}$ phase on day 7 of treatment was almost the same as that on day 4 in HSC-3-M3 and BICR6 cells (n.s.: not significant) (Figure 3D). There was a significantly increased percentage of cells in $\mathrm{S}$ phase on day 7 of treatment with the alternate-day regimen compared with control or consecutive-day regimen in HSC-3-M3 and BICR6 cells $(p<0.05)$ (Figure 3D).
Cyclin expression. The aforementioned effect of increased percentages of $\mathrm{S}$ phase cells with alternate-day treatment may be explained by $S$ phase arrest. Therefore, cyclin $\mathrm{A} / \mathrm{D} / \mathrm{E}$ expression in HSC-3-M3 cell lines was examined by western blotting analysis on day 7 of treatment from triplicate experiments (Figure 4). In the alternate-day regimen group, cyclin A and E expression levels were increased and cyclin D expression were decreased compared to that of the consecutive-day regimen. The presented image bands are representative of 3 independent experiments in Figure 4A. All the experiments showed the same trend, however differences were not statistically significant (Figure 4B). These results of western blot analysis are consistent with the cyclin expression pattern reported in $\mathrm{S}$ phase arrest $(18,19)$.

\section{Discussion}

We showed that the cytotoxic effect of alternate-day 5-FU treatment was not significantly different from that of consecutive-day 5-FU treatment in HSC-3-M3 and BICR6 cells. However, the percentage of S-phase cells on day 7 of treatment was significantly increased in the alternate-day regiment compared to that of the consecutive-day regimen, in both cell lines. In the alternate-day regimen, cyclin $\mathrm{A}$ and $\mathrm{E}$ expression was increased and cyclin D expression was decreased compared with that of the consecutive-day regimen. Shirasaka et al. examined the alternate-day $\mathrm{S}-1$ regimen and the relation between cell cycle length and antitumor activity of 5-FU (20). They stated that the theoretical basis by which alternate-day S-1 administration exerts its effect is as follows. Normal cells and tumor cells have different cell cycles in vivo. The cell cycle of normal cells is only 0.5-1.5 days, and the length of $\mathrm{S}$ phase, in which 5-FU was activated, was 9-14 h (21). In contrast, the cell cycle of tumor cells is 5-7 days and $\mathrm{S}$ phase lasted for $>17-60 \mathrm{~h}$. Therefore, drug withdrawal for 24 $\mathrm{h}$ allows proliferation of normal cells that do not encounter 5FU during their shorter $\mathrm{S}$ phase, while cancer cells are still exposed to 5-FU during their longer lasting $\mathrm{S}$ phase (20). In a study in which ovarian cancer cells were given intermittent dosing with 5-FU withdrawal time and consecutive 
A

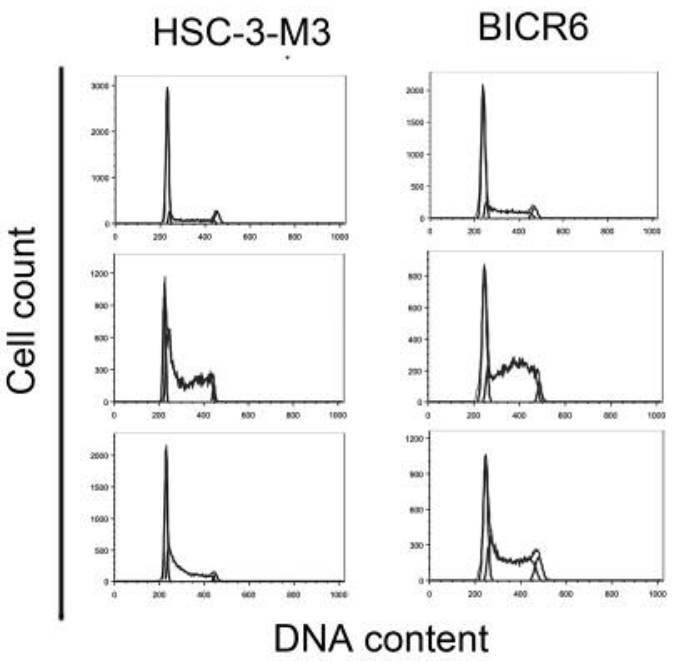

B

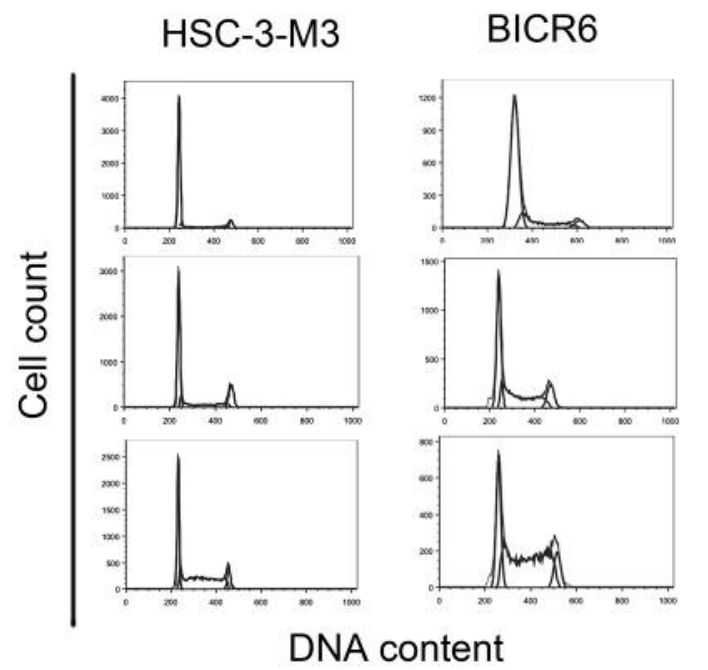

C

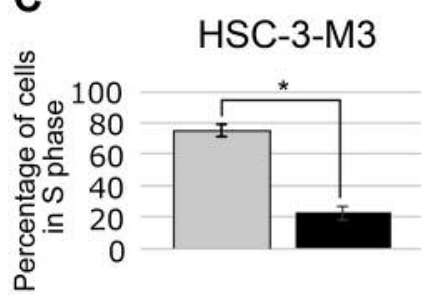

Consecutive-day treatment on day4

Consecutive-day treatment on day7

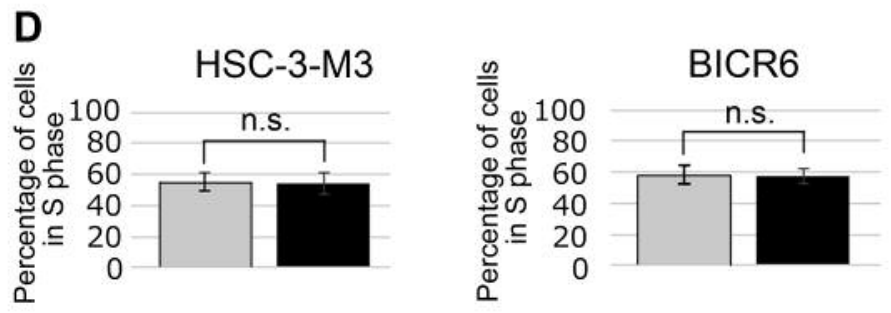

$\square$ Alternate-day treatment on day4

Alternate-day treatment on day7

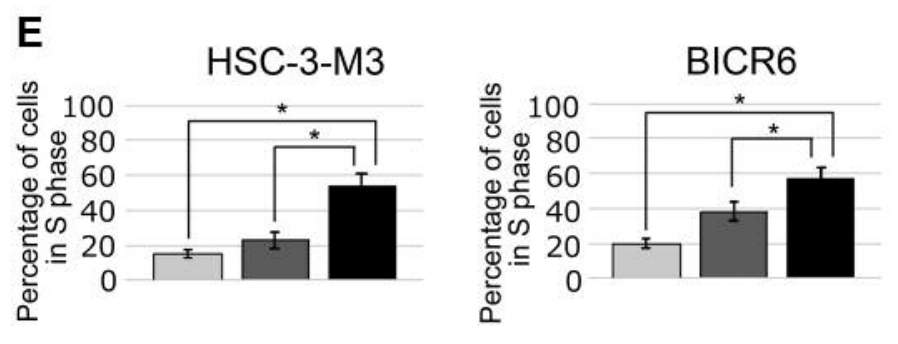

Control on day 7

Consecutive-day treatment on day7

Alternate-day treatment on day7

Figure 3. Cell cycle distributions were analyzed by flow cytometry. DNA distribution histogram using propidium iodide (PI) labeling ( $x$-axis) and total number of cells in each channel (y-axis) in control, consecutive-day 5-fluorouracil (consecutive) treatment, or alternate-day 5-fluorouracil (alternate) treatment cells. Cell cycle distributions were analyzed by flow cytometry $(A, B)$. In consecutive-day treatment, the percentage of cells in $S$ phase on day 7 was significantly decreased $(p<0.05)$ compared with that on day $4(C)$. By contrast, in alternate-day treatment, the percentage of cells in $S$ phase on day 7 was almost the same as that on day $4(D)$. Thus, the percentage of $S$ phase cells on day 7 was higher (p<0.05) in the alternate-day regimen compared with the consecutive-day regimen or control $(E)$.

administration, Saga et al. reported that the therapeutic effect of 5-FU is impaired when the intermittent administration withdrawal time is longer than the doubling time of cancer cells (17). The doubling times of HSC-3-M3 and BICR6 used in the present study were both $>24 \mathrm{~h}$. The resting time of 5FU was set to $24 \mathrm{~h}$. Our experimental result was consistent with the report by Saga et al. In flow cytometry, the proportion of cells in $\mathrm{S}$ phase on day 7 of treatment increased with alternate-day administration compared to consecutive-day administration. 5-FU only targets cycling cells and modulates cancer cell cycle status via one of the following three modes: i) loss or accumulation of S-phase cells; ii) $\mathrm{G}_{2} / \mathrm{M}$ block; and iii) $\mathrm{G}_{1} / \mathrm{S}$ arrest (22). In our case, the cyclin expression pattern suggested that the alternate-day 5 -FU regimen caused $\mathrm{S}$ phase 
A

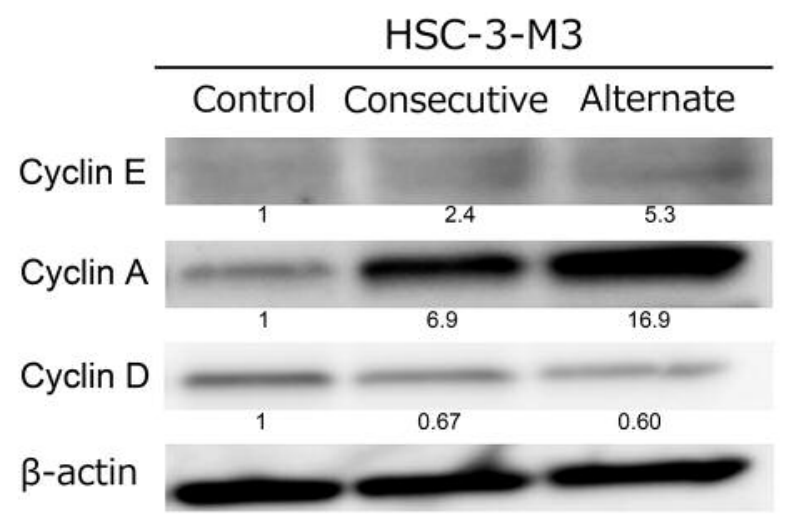

B

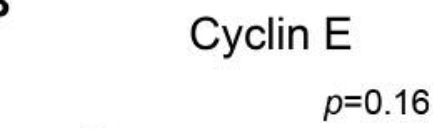

Cyclin A

$p=0.17$

Cyclin D
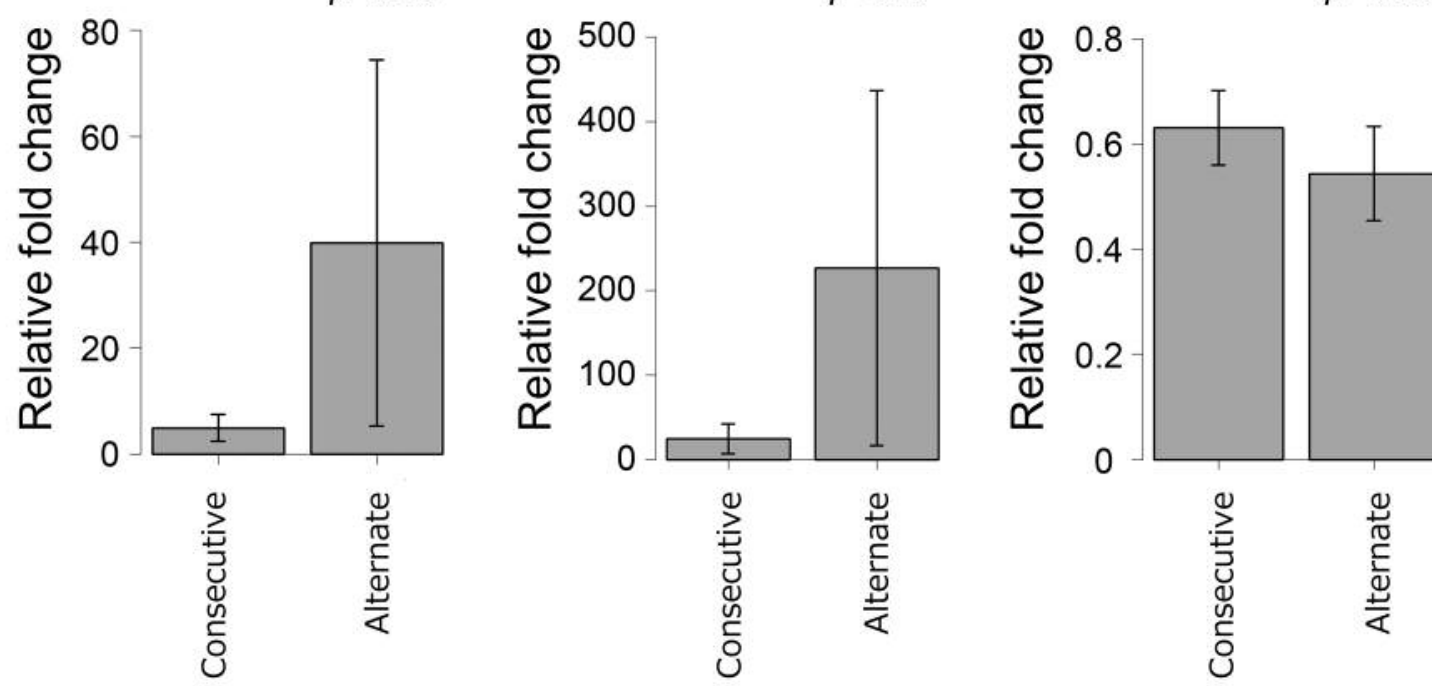

Figure 4. Protein levels of cyclins A, D, and E in HSC-3-M3 cell lines were assessed by western blot analysis. Expression levels of cyclins A/E were increased in the alternate-day regimen compared to that in the consecutive-day regimen. Conversely, cyclin $D$ expression was decreased in the alternate-day regimen compared to that in the consecutive-day regimen. Protein levels were quantified using $\beta$-actin as an internal control and were normalized to the control group (A). Data are presented as mean relative fold change compared to control \pm standard deviation and $p$-values (B).

arrest $(18,19)$. Because 5-FU acts on S-phase cells, S-phase arrest may increase susceptibility to the drug. In order to further improve the effectiveness and tolerability of alternateday 5-FU administration in head and neck cancer, further examination such as dose setting is warranted.

\section{Authors' Contributions}

YM conceived and carried out the experiments with the collaboration of YK, HS, RT, TK, MH, and YM. YM wrote the first draft. HS, YM, YK, and NK reviewed and revised the article.

\section{Acknowledgements}

We thank Dr. Ryuichiro Araki (Saitama Medical University International Medical Center) for assistance with statistical analysis. We also thank Ms. Noriko Akiyama (Saitama Medical University International Medical Center) and Mr. Takashi Yamaga (Kyorin University) for technical assistance.

This study was supported by a grant from Setsuro Fujii Memorial, The Osaka Foundation for Promotion of Fundamental Medical Research. The sponsors had no direct impact on study design or conduct; data collection, management, analysis, or interpretation; or preparation, review, or approval of the manuscript. 


\section{References}

1 Shirasaka T, Nakano K, Takechi T, Satake H, Uchida J, Fujioka A, Saito H, Okabe H, Oyama K, Takeda S, Unemi N and Fukushima M: Antitumor activity of $1 \mathrm{M}$ tegafur-0.4 M 5-chloro2,4-dihydroxypyridine-1 M potassium oxonate (S-1) against human colon carcinoma orthotopically implanted into nude rats. Cancer Res 56(11): 2602-2606, 1996. PMID: 8653704.

2 Huang SH and O'Sullivan B: Overview of the 8th Edition TNM Classification for Head and Neck Cancer. Curr Treat Options Oncol 18(7): 40, 2017. PMID: 28555375. DOI: 10.1007/s11864017-0484-y

3 Méry B, Rancoule C, Guy JB, Espenel S, Wozny AS, BattistonMontagne P, Ardail D, Beuve M, Alphonse G, RodriguezLafrasse C and Magné N: Preclinical models in HNSCC: A comprehensive review. Oral Oncol 65: 51-56, 2017. PMID: 28109468. DOI: $10.1016 /$ j.oraloncology.2016.12.010

4 Liu JC, Bhayani M, Kuchta K, Galloway T and Fundakowski C: Patterns of distant metastasis in head and neck cancer at presentation: Implications for initial evaluation. Oral Oncol 88: 131-136, 2019. PMID: 30616783. DOI: 10.1016/j.oraloncology.2018.11.023

5 Shirasaka T, Shimamato Y, Ohshimo H, Yamaguchi M, Kato T, Yonekura K and Fukushima M: Development of a novel form of an oral 5-fluorouracil derivative (S-1) directed to the potentiation of the tumor selective cytotoxicity of 5-fluorouracil by two biochemical modulators. Anticancer Drugs 7(5): 548-557, 1996. PMID: 8862723.

6 Tsukahara K, Kubota A, Hasegawa Y, Takemura H, Terada T, Taguchi T, Nagahara K, Nakatani H, Yoshino K, Higaki Y, Iwae S, Beppu T, Hanamure Y, Tomita K, Kohno N, Kawabata K16, Fukushima M, Teramukai S and Fujii M; ACTS-HNC group: Randomized phase III trial of adjuvant chemotherapy with S-1 after curative treatment in patients with squamous-cell carcinoma of the head and neck (ACTS-HNC). PLoS One 10(2): e0116965, 2015. PMID: 25671770. DOI: 10.1371/journal.pone.0116965

7 Sakuma K, Hosoya Y, Arai, W, Haruta, H, Ui, T, Kurashina, K, Saito, S, Hirashima, Y, Yokoyama T, Zuiki T, Hyodo M, Nagai $\mathrm{H}$, Yasuda Y and Shirasaka T: Alternate-day treatment with S-1 in patients with gastric cancer: a retrospective study of strategies for reducing toxicity. Int J Clin Oncol 15(2): 166-171, 2010. PMID: 20195683. DOI: 10.1007/s10147-010-0036-y

8 Yamaue H, Satoi S, Kanbe T, Miyazawa M, Tani M, Kawai M, Hirono S, Okada K, Yanagimoto H, Kwon AH, Mukouyama T, Tsunoda H, Chijiiwa K, Ohuchida J, Kato J, Ueda K, Yamaguchi T, Egawa S, Hayashi K and Shirasaka T: Phase II clinical study of alternate-day oral therapy with S-1 as first-line chemotherapy for locally advanced and metastatic pancreatic cancer. Cancer Chemother Pharmacol 73(1): 97-102, 2014. PMID: 24146260. DOI: $10.1007 / \mathrm{s} 00280-013-2323-6$

9 Moro Y, Kogashiwa Y, Sato D, Matsumoto Y, Nakamura T, Yamauchi K, Sakurai H and Kohno N: Feasibility study of alternate-day S-1 as adjuvant chemotherapy for head and neck cancer. Anticancer Res 35(2): 977-981, 2015. PMID: 25667484.

10 Arai W, Hosoya Y, Haruta H, Kurashina K, Saito S, Hirashima Y, Yokoyama T, Zuiki T, Sakuma K, Hyodo M, Yasuda Y, Nagai $\mathrm{H}$ and Shirasaka $\mathrm{T}$ : Comparison of alternate-day versus consecutive-day treatment with S-1: assessment of tumor growth inhibition and toxicity reduction in gastric cancer cell lines in vitro and in vivo. Int J Clin Oncol 13(6): 515-520, 2008. PMID: 19093179. DOI: 10.1007/s10147-008-0780-4
11 Matsui T, Ota T, Ueda Y, Tanino M and Odashima S: Isolation of a highly metastatic cell line to lymph node in human oral squamous cell carcinoma by orthotopic implantation in nude mice. Oral Oncol 34(4): 253-256, 1998. PMID: 9813718.

12 Rikimaru K, Toda H, Tachikawa N, Kamata N and Enomoto S: Growth of the malignant and nonmalignant human squamous cells in a protein-free defined medium. In Vitro Cell Dev Biol 26(9): 849-856, 1990. PMID: 2228902.

13 Momose F, Araida T, Negishi A, Ichijo H, Shioda S and Sasaki S: Variant sublines with different metastatic potentials selected in nude mice from human oral squamous cell carcinomas. J Oral Pathol Med 18(7): 391-395, 1989. PMID: 2585303.

14 Edington KG, Loughran OP, Berry IJ and Parkinson EK: Cellular immortality: a late event in the progression of human squamous cell carcinoma of the head and neck associated with p53 alteration and a high frequency of allele loss. Mol Carcinog 13(4): 254-265, 1995. PMID: 7646764.

15 Kamalidehghan B, Houshmand M, Kamalidehghan F, Jafarzadeh $\mathrm{N}$, Azari S, Akmal SN and Rosli R: Establishment and characterization of two human breast carcinoma cell lines by spontaneous immortalization: Discordance between estrogen, progesterone and HER2/neu receptors of breast carcinoma tissues with derived cell lines. Cancer Cell Int 12(1): 43, 2012. PMID: 23106969. DOI: 10.1186/1475-2867-12-43

16 Kanda, Y: Investigation of the freely available easy-to-use software 'EZR' for medical statistics. Bone Marrow Transplant 48(3): 452-458, 2013. PMID: 23208313. DOI: 10.1038/bmt. 2012.244

17 Saga Y, Suzuki M, Sato I and Shirasaka T: An in vitro examination of a 5-fluorouracil regimen involving continuous venous infusion using cultured cell lines derived from ovarian cancers. Oncol Rep 7(3): 625-628, 2000. PMID: 10767380. DOI: 10.3892/or.7.3.625

18 Yuan Z, Guo W, Yang J, Li L, Wang M, Lei Y, Wan Y, Zhao X, Luo N, Cheng P, Liu X, Nie C, Peng Y, Tong A and Wei Y: PNAS-4, an early DNA damage response gene, induces $S$ phase arrest and apoptosis by activating checkpoint kinases in lung cancer cells. J Biol Chem 290(24): 14927-14944, 2015. PMID: 25918161. DOI: 10.1074/jbc.M115.658419

19 Li L, Chen DB, Lin C, Cao K, Wan Y, Zhao XY, Nie CL, Yuan $\mathrm{Z}$ and Wei YQ: hPNAS-4 inhibits proliferation through $\mathrm{S}$ phase arrest and apoptosis: underlying action mechanism in ovarian cancer cells. Apoptosis 18(4): 467-479, 2013. PMID: 23322088. DOI: $10.1007 / \mathrm{s} 10495-012-0797-\mathrm{z}$

20 Shirasaka T: Development history and concept of an oral anticancer agent S-1 (TS-1): its clinical usefulness and future vistas. Jpn J Clin Oncol 39(1): 2-15, 2009. PMID: 19052037. DOI: $10.1093 /$ jjco/hyn127

21 Clarkson B, Ota K, Ohkita T and O'Connor A: Kinetics of proliferation of cancer cells in neoplastic effusions in man. Cancer 18(10): 1189-1213, 1965. PMID: 5890960. DOI: 10.1002/10970142(196510)18:10<1189::aid-cncr2820181002>3.0.co;2-8

22 Guo X, Goessl E, Jin G, Collie-Duguid ES, Cassidy J, Wang W and O'Brien V: Cell cycle perturbation and acquired 5fluorouracil chemoresistance. Anticancer Res 28(1A): 9-14, 2008. PMID: 24922653.

Received August 15, 2019 Revised September 17, 2019 Accepted September 27, 2019 